\title{
Morinda citrifolia L. leaf extract prevent weight gain in Sprague-Dawley rats fed a high fat diet
}

\author{
Najla Gooda Sahib Jambocus ${ }^{a}$, Amin Ismail ${ }^{b}$, Alfi Khatibc, Fawzi Mahomoodallyd, Nazamid Saaria, \\ Muhammad Waseem Mumtaz ${ }^{\text {,ff }}$ and Azizah Abdul Hamid ${ }^{\mathrm{a}, \mathrm{e}}$
}

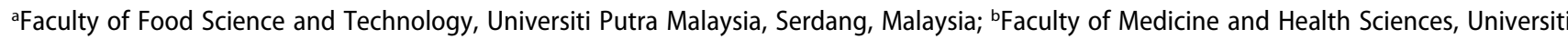
Putra Malaysia, Serdang, Malaysia; 'Department of Pharmaceutical Chemistry, Kulliyyah of Pharmacy, International Islamic University Malaysia, Kuantan, Malaysia; ${ }^{d}$ Department of Health Sciences, Faculty of Science, University of Mauritius, Reduit, Mauritius; ${ }^{\text {eHalal Product }}$ Research Institute, Universiti Putra Malaysia, Serdang, Malaysia; fDepartment of Chemistry, University of Gujrat, Gujrat, Pakistan

\begin{abstract}
Background: Morinda citrifolia L. is widely used as a folk medicinal food plant to manage a panoply of diseases, though no concrete reports on its potential anti-obesity activity. This study aimed to evaluate the potential of M. citrifolia leaf extracts (MLE60) in the prevention of weight gain in vivo and establish its phytochemical profile.

Design: Male Sprague-Dawley rats were divided into groups based on a normal diet (ND) or high fat diet (HFD), with or without MLE60 supplementation (150 and $350 \mathrm{mg} / \mathrm{kg}$ body weight) and assessed for any reduction in weight gain. Plasma leptin, insulin, adiponectin, and ghrelin of all groups were determined. ${ }^{1} \mathrm{H}$ NMR and LCMS methods were employed for phytochemical profiling of MLE60.

Results: The supplementation of MLE60 did not affect food intake indicating that appetite suppression might not be the main anti-obesity mechanism involved. In the treated groups, MLE60 prevented weight gain, most likely through an inhibition of pancreatic and lipoprotein activity with a positive influence on the lipid profiles and a reduction in LDL levels. MLE60 also attenuated visceral fat deposition in treated subjects with improvement in the plasma levels of obesity-linked factors. 'Spectral analysis showed the presence of several bioactive compounds with rutin being more predominant.

Conclusion: MLE60 shows promise as an anti-obesity agents and warrants further research.
\end{abstract}

\section{ARTICLE HISTORY}

Received 11 April 2017

Accepted 26 May 2017

\section{KEYWORDS}

Morinda citrifolia; high fat diet; anti-obesity; pancreatic lipase; lipoprotein lipase; flavonoids

\section{Introduction}

There are four hundred million obese (body mass index $\left.(\mathrm{BMI})>30 \mathrm{~kg} \mathrm{~m}^{-2}\right)$ and 1.6 billion overweight $(\mathrm{BMI}=$ 25.0-29.9 $\mathrm{kg} \mathrm{m}^{-2}$ ) people worldwide. Overweight and obese people have an increased risk factor for diabetes, cardiovascular diseases, and certain cancers [1]. Large cohort studies have also reported obesity to be independently related to increased oxidative stress in both men and women [2]. The positive correlation between increased level of C-reactive protein (CRP) and obesity confirm the fact that this disease is also a chronic inflammatory state, which can potentially lead to cardiovascular diseases [3]. Both developed and developing nations have not been spared by this public health burden. For instance, $16.3 \%$ and $6.3 \%$, respectively, of Malaysian's primary school children in an urban setting were found to be overweight and obese. The nutritional status of these Malaysian children was significantly related to blood pressure, history of breast-feeding, socio-economic factors, parents' education level, and consumption of fast foods and sugary beverages [4]. One of the main causes of obesity is the consumption of diets high in fats. It is predicted that $51 \%$ of the American population will be obese by 2030 , and if the obesity prevalence were to be maintained at its current levels, US $\$ 549.5$ billion would be saved in terms of health care expenditure [5]. Effort to prevent and manage obesity is therefore primordial. Currently, there are limited drugs available for long-term treatment and management of obesity with proven efficacy and present drug development is still challenging due to the multifaceted nature of the disease [6]. There has been much effort to develop new anti-obesity agents from natural sources such as medicinal plants. Plant bioactive compounds, also termed phytochemicals, have been reported to possess anti-obesity effects through numerous mechanisms, such as inhibition of digestive and metabolic lipases, suppression of appetite, increase in thermogenesis, 
and inhibition of pre-adipocytes proliferation and differentiation $[7,8]$. Several reports on the anti-obesity effect of plant extracts in animal-based models of obesity have been published [9-12].

The potential anti-obesity effect of Morinda citrifolia L. fruit extracts in vitro has been previously reported $[7,13]$. The leaves, fruits, and roots of M. citrifolia L. are widely used in folk medicine in Southeast Asia, Polynesia, Tahiti, Australia, and Hawaii [14] and are associated with many health-promoting properties. It is believed to protect against inflammatory diseases such as diabetes and against oxidative stress [15]. Leaves of $M$. citrifolia $\mathrm{L}$. are most commonly used in tablet forms as tea [16]. However, there is still a dearth of scientific validation of the potential antiobesity effect of $M$. citrifolia L. leaves in vivo.

The present study was geared towards evaluating the potential of M. citrifolia leaf extracts (MLE60) in the prevention of weight gain in vivo and establish its phytochemical profile. Male Sprague-Dawley rats were divided into groups based on a normal diet (ND) or high fat diet (HFD), with or without two different doses (150 and $350 \mathrm{mg} / \mathrm{kg}$ body weight) of MLE60 supplementation and assessed for the prevention of weight gain. A number of plasma biomarkers (blood glucose level, total cholesterol (TC), low-density lipoprotein (LDL), high-density lipoprotein (HDL), triglycerides (TG), urea nitrogen, creatinine, $\gamma$-glutamyltransferase (GTT), alanine aminotransferase (ALT), aspartate aminotransferase (AST), and alkaline phosphatase activity (ALP)) were measured in the treated and untreated HFD groups and compared with rats fed on the ND. Plasma leptin, insulin, adiponectin, and ghrelin were determined using standard methods. Total phenolic content (TPC), DPPH radical scavenging, and pancreatic and lipoprotein lipase activity were determined. ${ }^{1} \mathrm{H}$ nuclear magnetic resonance (NMR) and liquid chromatography mass spectroscopy (LCMS) methods were employed for phytochemical profiling of MLE60.

\section{Materials and methods}

\section{Collection and extraction of raw materials}

Fresh mature leaves of $M$. citrifolia were collected from Bukit Expo, Universiti Putra Malaysia. A voucher specimen (SK 2197/13) was deposited at the herbarium, Institute of Bioscience, Universiti Putra Malaysia, and the species was confirmed as M. citrifolia L. by a local botanist. Leaves were collected consistently in the morning, from 10 to 11 o'clock, on sunny days, from five representative trees. The leaves were cleaned and treated with liquid nitrogen for immediate quenching of metabolites and were stored at $-80^{\circ} \mathrm{C}$ for $24 \mathrm{~h}$. The frozen leaves were then lyophilised under vacuum, until constant weight $(48-72 \mathrm{~h})$, ground, and stored at $-80^{\circ} \mathrm{C}$ until further use. Powdered leaves (10 g) were extracted with $100 \%-60 \%$ ethanol for $72 \mathrm{~h}$ at room temperature. The solvent was filtered out every $24 \mathrm{~h}$ and the pooled filtrate was evaporated using a rotary evaporator until a viscous extract was obtained. Crude extracts were lyophilised under vacuum until constant weight $(36-48 \mathrm{~h})$ and kept at $-80^{\circ} \mathrm{C}$ until further use. They were defined as MLE100, MLE80, MLE60, MLE50, and MLE40 based on the percentage of ethanol used in the extractions.

\section{${ }^{1} H$ NMR measurement and data analysis}

MLE60 (25 mg) were dissolved in $0.375 \mathrm{~mL}$ of $\mathrm{CH}_{3} \mathrm{OH}$ $d_{4}$ without any internal standard and $0.375 \mathrm{~mL}$ of $\mathrm{KH}_{2} \mathrm{PO}_{4}$ buffer in $\mathrm{D}_{2} \mathrm{O}$ (pH 6 adjusted with $\mathrm{NaOD}$ ) containing $0.1(\mathrm{w} / \mathrm{w})$ TSP. The mixture was vortexed for $1 \mathrm{~min}$ and ultrasonicated for $10 \mathrm{~min}$ at room temperature. The solution was then centrifuged at $13,000 \mathrm{~g}$ for $10 \mathrm{~min}$ and $600 \mu \mathrm{L}$ of the supernatant was transferred to a $5 \mathrm{~mm}$ NMR tube and subjected to ${ }^{1} \mathrm{H}$ NMR analysis [17]. Spectra were acquired at $27^{\circ} \mathrm{C}$ on a Varian Unity INOVA $500 \mathrm{MHz}$ spectrometer (Varian Inc, CA), with a frequency of $499.887 \mathrm{MHz}$. For each sample, 64 scans were recorded with an acquisition time of $193 \mathrm{~s}$, pulse width of $3.75 \mu \mathrm{s}$ and relaxation delay of $1.0 \mathrm{~s}$. Additional two-dimensional (2D) ${ }^{1} \mathrm{H}-{ }^{1} \mathrm{H} J$ resolution was performed to aid in the identification of certain metabolites.

\section{TPC}

TPC was quantified using the Folin-Ciocalteau method, as proposed by Singleton at al. [18]. Methanolic extracts $(0.5 \mathrm{~mL}), 0.5 \mathrm{~mL}$ Folin-Ciocalteau, and $10 \mathrm{~mL}$ of $7 \%$ of sodium carbonate were allowed to react for $1 \mathrm{~h}$. The resulting blue complex was read at $725 \mathrm{~nm}$ (Shimadzu UV visible Spectrophotometer, UV-1650 PC, Japan).

\section{DPPH radical scavenging activity}

The antioxidant activity of the extracts was determined on their ability to scavenge DPPH radicals, based on a modified method of Brand-Williams et al. [19]. Different concentrations of MLE60 was dissolved $(0.25 \mathrm{~mL})$ in methanol were mixed with $1.75 \mathrm{~mL}$ of 6 $\times 10^{-5} \mathrm{~mol}$ of DPPH solution in a 12 -well plate and allowed to stand for $30 \mathrm{~min}$ at room temperature, in the dark. Pure methanol was used as baseline control. The absorbance value was read at $515 \mathrm{~nm}$ using an Elisa plate reader (Biotek, EL 800). Antioxidant activity 
was reported as $\mathrm{IC}_{50}$, define by the concentration of samples required $(\mathrm{mg} / \mathrm{mL})$ to scavenge $50 \%$ of the free radicals. Butylated hydroxyanisole (BHA) and $\alpha$ tocopherol were used as positive controls for synthetic and natural antioxidant respectively.

\section{Pancreatic and lipoprotein lipase activity}

Pancreatic and lipoprotein lipase activity was carried out based on previous methods, as described elsewhere $[7,13]$, both titrimetric methods based on the quantification of free fatty acids released in a substrate, lipase and extract system as compared to a substrate and lipase system only.

\section{LCMS analysis}

Dried extract $(10 \mathrm{mg}$ ) was suspended in $1 \mathrm{~mL}$ methanol and filtered through a PTFE filter (pore size $0.22 \mu \mathrm{m}$ ). The analysis was carried out on a LTQ Trap mass spectrometer (Thermo Scientific) with U-HPLC system (Accela). Spectral $\mathrm{m} / \mathrm{z}$ from $100-1000$ was recorded and the $\mathrm{MS}^{\mathrm{n}}$ fragmentation was carried out with $35-40 \%$ collision energy. Electrospray ionisation conditions were as follows: source accelerating voltage $4.0 \mathrm{kV}$; capillary temperature, $275^{\circ} \mathrm{C}$; sheath gas flow, 40 arb; auxiliary gas, 20 arb. A Hypersil Gold RP $\mathrm{C}_{18}$ column $(2.1 \mathrm{~mm} \mathrm{ID} \times 100 \mathrm{~mm}, 3 \mu \mathrm{m})$ was used for elution. Aqueous formic acid $(0.1 \%)$ and acetonitrile were used as eluting solvents. A flow rate of $200 \mu \mathrm{L} / \mathrm{min}$ and an injection volume of $5 \mu \mathrm{L}$ were used.

\section{HPLC analysis of MLE60}

Dried extract $(10 \mathrm{mg}$ ) was dissolved in $1 \mathrm{~mL}$ methanol and filtered through a $0.45 \mu \mathrm{m}$ (Whatman) nylon membrane filter prior to injection into HPLC system. Analysis was run in triplicates. MLE60 was profiled for commonly present flavonoids (rutin, kaempherol, quercetin, myricetin, fisetin, hesperitin, quercitrin, naringin, and genistein. Major identified compounds were further quantified using a standard curve. Standards (60-140 ppm) were dissolved in methanol for quantification. The HPLC system consisted of a Waters Delta 600 , with a 600 controller and photodiode array detector (Waters 996). The column used was a Phenomenex-Luna $(5 \mu \mathrm{m}) \mathrm{PFP}[2]$ column $(4.6 \mathrm{~mm}$ ID $\times 250 \mathrm{~mm})$ and two eluting solvents were used. Solvent A was $0.1 \%$ aqueous formic acid and solvent $\mathrm{B}$ was acetonitrile. A flow rate of $1.0 \mathrm{~mL} / \mathrm{min}$ and an injection volume of $10 \mu \mathrm{L}$ were used. Retention times, peak areas, and UV spectra of major compounds were further analysed.

\section{Animal experiment}

Male Sprague-Dawley rats (5 weeks old) were purchased from Sapphire Enterprise, Malaysia and acclimatised for 10 days under standard laboratory conditions (12 h light/dark cycle, 55-60\% relative humidity, $\left.23-25^{\circ} \mathrm{C}\right)$. After acclimatisation, rats were randomly divided into two groups based on assigned diets: standard rat chow (Gold Coin, Malaysia) and an HFD (MP Diets, USA). The composition of the both diets is given in Table 1. Animals in both groups were further subdivided into the following groups $(n=6)$, based on supplementation or non-supplementation with MLE60:

- $\mathrm{ND}=$ normal diet only

- $\mathrm{ND}+150=$ normal diet $+150 \mathrm{mg} / \mathrm{kg}$ body weight of MLE60

- $\mathrm{ND}+350=$ normal diet $+350 \mathrm{mg} / \mathrm{kg}$ body weight MLE60

- HFD = high fat diet only

Table 1. Composition of experimental diets.

\begin{tabular}{|c|c|c|c|}
\hline \multicolumn{2}{|c|}{$\begin{array}{c}\text { Normal diet (ND) Standard rat chow Gold Coin, Malaysia } \\
(3.27 \mathrm{kcal} / \mathrm{g})\end{array}$} & \multicolumn{2}{|c|}{$\begin{array}{l}\text { High fat diet (HFD) High saturated fat diet MP Diets, USA } \\
\text { (Cat Num } 960,242)(4.39 \mathrm{kcal} / \mathrm{g})\end{array}$} \\
\hline Ingredients & Percentage/amount & Ingredients & Percentage/amount \\
\hline Crude protein & $21-23 \%$ & Casein purified & $20 \%$ \\
\hline Crude fibre & $5.0 \%$ & DL-Methionine & $0.3 \%$ \\
\hline Crude fat & $3.0 \%$ & Sucrose & $30.58 \%$ \\
\hline Moisture & $3.0 \%$ & Corn starch & $20 \%$ \\
\hline Calcium & $0.8-1.2 \%$ & Coconut oil hydrogenated & $20 \%$ \\
\hline Phosphorus & $0.8-1.2 \%$ & Alphacel-non-nutritive bulk & $5 \%$ \\
\hline Nitrogen-free extract & $49.0 \%$ & DL-a-Tocopherol powder $(250 \mathrm{lU} / \mathrm{g})$ & $0.12 \%$ \\
\hline Vitamin A & $10 \mathrm{MIU}$ & AIN-76 Mineral Mix & $4.0 \%$ \\
\hline Vitamin $D_{3}$ & $2.5 \mathrm{MIU}$ & \multirow{2}{*}{\multicolumn{2}{|c|}{$\begin{array}{l}\text { MP Vitamin Diet Fortification mixture } 1.2 \mathrm{X} \text { normal } \\
\text { amount }\end{array}$}} \\
\hline Vitamin E & $15 \mathrm{~g}$ & & \\
\hline
\end{tabular}

AIN-76 mineral mix contains the following (per $1000 \mathrm{~g}$ ): calcium phosphate dibasic $500 \mathrm{~g}$, sodium chloride $74 \mathrm{~g}$, potassium citrate monohydrate $220 \mathrm{~g}$ potassium sulphate $52 \mathrm{~g}$, magnesium oxide $24 \mathrm{~g}$, magnesium carbonate $3.5 \mathrm{~g}$, ferric citrate $6 \mathrm{~g}$, zinc carbonate $1.6 \mathrm{~g}$, cupric carbonate $0.3 \mathrm{~g}$, potassium iodate $0.01 \mathrm{~g}$, sodium selenite $0.01 \mathrm{~g}$, chromium potassium sulphate $0.55 \mathrm{~g}$, sucrose $118 \mathrm{~g}$. 
- HFD+150 = high fat diet $+150 \mathrm{mg} / \mathrm{kg}$ body weight MLE60

- $\mathrm{HFD}+350=$ high fat diet $+350 \mathrm{mg} / \mathrm{kg}$ body weight MLE60

\section{Administration of MLE 60}

Animals were allowed their respective diets ad libitum and appropriate dosage of MLE60 was given through gastric intubation using a force-feeding needle. Volume of extracts given per day did not exceed $3.0 \mathrm{~mL}$. Control groups received the carrier vehicle $(0.03 \%$ $\mathrm{CMC}$ ) through gastric intubation. Rats were allowed a sedentary lifestyle, without any specific physical activity regime for the course of the experiment.

\section{Measurement of body weight, food intake and collection of faeces}

Body weight of rats was measured weekly using a weighing balance. The $\%$ weight gain was calculated as: (body weight on specific week ( $g$ ) - initial body weight)/initial body weight $\times 100$.

Food intake was measured once a week over $24 \mathrm{~h}$ based on the weight of leftover feed out of $100 \mathrm{~g}$ given. Faecal samples were recorded at the middle (week 6) and at the final stage (week 12) of the study using metabolic cages over a period of $18 \mathrm{~h}$.

\section{Sacrifice of animals}

After 12 weeks of treatment, animals were weighed and sacrificed by cardiac puncture under an anaesthetic effect (xylazine + ketamine). Rats were deprived of food for $12 \mathrm{~h}$ prior to sacrifice. Serum and plasma samples were separated at $1500 \mathrm{~g}$ for $15 \mathrm{~m}$ and stored at $-80^{\circ} \mathrm{C}$ for further analysis. Organs (liver, kidney, lung, heart, testis, and adipose tissue) were weighed, rinsed with saline, and fixed in $10 \%$ formalin for histopathological analysis. All animals were handled according to the international principles of the use and handling of experimental animals (US National Institute of Health, 1985) and all the protocols were approved by the Animal House and Use Committee of the Faculty of Medicine and Health Sciences, Universiti Putra Malaysia (Approval no: UPM/FPSK/PADS/BR. UUH/00462).

\section{Blood biochemistry}

Rats were fasted for $12 \mathrm{~h}$ before blood glucose measurement. Food was removed from the food dispenser and bedding of the cages was changed to avoid coprophagy. Blood from the tail vein was measured for glucose using the OneTouch Basic glucose monitor (Lifescan) and reported as $\mathrm{mmol} / \mathrm{L}$. Blood glucose level was measured during the study and prior to sacrifice. TC, LDL, HDL, TG, urea nitrogen, creatinine, GGT, ALT, AST, and ALP activity were measured on a Roche/Hitachi cobac $\mathrm{C}$ system and results were expressed in U/L (Roche Diagnostics $\mathrm{GmbH}$, Sandhofer, Strasse, Mannheim), following manufacturers' protocols. Plasma leptin, insulin, adiponectin, and ghrelin were determined using enzyme-linked immunoabsorbent assay (ELISA) kits following manufacturer's instruction (leptin: RayBio ${ }^{\circledR}$ Rat Leptin ELISA Kit, Cat \# ELR-Leptin-001, Norcross, GA, USA; insulin: Mercodia Rat Insulin ELISA, Uppsala, Sweden; adiponectin: Assay-Max Rat Adiponectin ELISA kit, Cat\# ERA2500-1; ghrelin: RayBio ${ }^{\circledR}$ Rat Ghrelin ELISA kit, Cat\# EIA-GHR-1, Norcross, GA, USA).

\section{Determination of faecal fat content}

Faecal lipid content was determined according to a modified method of Tsujita et al. (2006, 20). Faces were collected at the middle (week 6) and end (week 12) of the experiment. Faces $(0.5 \mathrm{~g})$ were soaked in $2 \mathrm{~mL}$ of deionised water for $24 \mathrm{~h}$ at $4^{\circ} \mathrm{C}$, followed by homogenisation by vortexing at high speed for 60 seconds. Lipids were extracted with $7.5 \mathrm{~mL}$ of methanol: chloroform $(2: 1, \mathrm{v}: \mathrm{v})$ and shaken for $30 \mathrm{~m}$, followed by addition of $2.5 \mathrm{~mL}$ of deionised water and $2.5 \mathrm{~mL}$ of chloroform and further shaking for $30 \mathrm{~m}$. Mixture was then centrifuged at $2000 \mathrm{~g}$ for $15 \mathrm{~min}$ and the lipophilic layer from the extraction was collected and dried under vacuum. Total fat content was weighed using a laboratory balance.

\section{Statistical analysis}

Data is expressed as mean \pm standard deviation (SD). Difference between groups was determined by one-way analysis of variance (ANOVA, MINITAB, version 14.0). Values were considered to be significantly different at the level of $p<0.05$. In the analysis of faecal fat content (week 6 and week 12) and body weights (before and after treatment), significance was further confirmed with one sample $t$ test.

\section{Results and discussion}

\section{Bioactive content and bioactivity of different extracts of M. citrifolia leaf}

The extracts were assessed for their TPC, DPPH scavenging potential and inhibitory effect on pancreatic 
Table 2. TPC, DPPH scavenging activity, and PL and LPL inhibiting activity of extracts of $M$. citrifolia leaves of different maturity.

\begin{tabular}{lcccc}
\hline Samples & $\begin{array}{c}\text { TPC } \\
\text { (g GA equivalent/ } 100 \mathrm{~g} \text { extract) }\end{array}$ & $\begin{array}{c}\text { DPPH scavenging activity } \\
\left(\mathrm{IC}_{50}(\mathrm{mg} / \mathrm{mL})\right.\end{array}$ & $\begin{array}{c}\text { Inhibition of PL activity } \\
\text { at } 0.625 \mathrm{mg} / \mathrm{mL}(\%)\end{array}$ & $\begin{array}{c}\text { Inhibition of LPL activity } \\
\text { at } 1 \mathrm{mg} / \mathrm{mL}(\%)\end{array}$ \\
\hline Mature (100:0) & $8.98 \pm 0.233^{\mathrm{b}}$ & $1.05 \pm 0.320^{\mathrm{c}}$ & $6.00 \pm 1.13^{\mathrm{c}}$ & $11.80 \pm 0.11^{\mathrm{bc}}$ \\
Mature (80:20) & $8.45 \pm 1.230^{\mathrm{b}}$ & $1.00 \pm 0.201^{\mathrm{c}}$ & $8.95 \pm 2.47^{\mathrm{bc}}$ & $8.93 \pm 1.88^{\mathrm{b}}$ \\
Mature (60:40) & $11.85 \pm 0.134^{\mathrm{a}}$ & $0.86 \pm 0.055^{\mathrm{b}}$ & $12.75 \pm 2.05^{\mathrm{bb}}$ & $15.18 \pm 1.53^{\mathrm{a}}$ \\
Mature (50:50) & $11.29 \pm 1.153^{\mathrm{ab}}$ & $0.79 \pm 0.104^{\mathrm{b}}$ & $9.50 \pm 0.42^{\mathrm{bc}}$ & $14.44 \pm 0.41^{\mathrm{a}}$ \\
Mature (40:60) & $10.11 \pm 0.103^{\mathrm{ab}}$ & $0.90 \pm 0.096^{\mathrm{b}}$ & $6.70 \pm 0.99^{\mathrm{c}}$ & $13.46 \pm 1.80^{\mathrm{a}}$ \\
BHA & $\mathrm{NA}$ & $0.02 \pm 0.001^{\mathrm{a}}$ & $\mathrm{NA}$ & $\mathrm{NA}$ \\
Tocopherol & $\mathrm{NA}$ & $0.04 \pm 0.001^{\mathrm{a}}$ & $\mathrm{NA}$ & $\mathrm{NA}$ \\
Orlistat & $\mathrm{NA}$ & $\mathrm{NA}$ & $18.23 \pm 2.51^{\mathrm{a}}$ & $\mathrm{NA}$ \\
Epicatechin & $\mathrm{NA}$ & $\mathrm{NA}$ & $3.30 \pm 0.42^{\mathrm{d}}$ & $11.89 \pm 1.37^{\mathrm{ab}}$ \\
\hline
\end{tabular}

Different small letters denote significant difference between the extracts for the same activity. Mature (100:0) indicate mature leaves extracted with 100\% (v: v) ethanol:water; Mature (80:20) indicates 80:20 (v:v) ethanol:water; etc. Statistical analysis has been carried out using MINITAB 14 and significance value set at $p<0.05$. All analysis was repeated three times, with triplicate readings.

and lipoprotein lipase as a preliminary evaluation (Table 2). Mature leaves of M. citrifolia were extracted using different concentration of ethanol:water (10060:0-40). Leaves extracted with 60-40\% ethanol had higher TPC and DPPH scavenging activity whereas leaves extracted with $100-80 \%$ ethanol had higher content of TFC (Table 2). Different solvent systems have been used to extract polyphenols from plants, with varying results. Polar solvents are most suitable for extraction of polyphenols from a plant matrix, with ethanol, methanol, acetone, and ethyl acetate being the usual solvent of choice [21]. A bi-solvent system has been proposed to be more efficient than a single pure solvent. Sultana et al. previously showed that in general a higher extraction yield, phenolic content, and antioxidant activity was obtained in an aqueous based solvent system as compared to a pure solvent system [22]. More specific to M. citrifolia, a binary solvent extraction system (40\% ethanol and 60\% water) for $80 \mathrm{~min}$ at $65^{\circ} \mathrm{C}$ had the highest recovery of total phenolic and flavonoids compounds, showing a positive correlation with the antioxidant capacity [23]. Results of this study is in accordance to reports found in literature which support that lower concentrations of ethanol (50\%) manages to extract more polyphenols and show more potent antioxidant activity as compared that of pure ethanol.

An ethanol water system is commonly used for extraction as not only it can dissolve a wide range of polyphenols, but also is accepted for human consumption [24]. The different extracts of the mature leaves were also assessed for their inhibitory activity on pancreatic and lipoprotein lipase in vitro. At a low concentration of $0.625 \mathrm{mg} / \mathrm{mL}$, mature leaves extracted with $60 \%$ ethanol inhibited pancreatic lipase (PL) by $12.75 \pm 2.05 \%$ as compared to pure epicatechin, which showed a mild inhibition of $3.30 \pm 0.42 \%$ (Table 2). At this concentration, the inhibition was not significantly different from that of Orlistat ${ }^{\oplus}$, which was used as positive control. The extracts also showed inhibition of lipoprotein lipase activity. At $1 \mathrm{mg} /$
$\mathrm{mL}$, mature $M$. citrifolia leaves extracted with lower concentration of ethanol (60-50\%) had the highest percentage inhibition with $15.17 \pm 1.53$ to $13.46 \pm 1.80$, which was not significantly different from the inhibition achieved by pure epicatechin at $11.89 \pm 1.37 \%$. Grape seed extract and peanut seed extract $(0.1 \mathrm{mg} / \mathrm{mL})$ showed $22 \%$ and $39 \%$, respectively, inhibition of human PL activity as measured with the Lipase PS kit [25]. Four hundred plants were screened for their anti-obesity activity by assessing their effect on PL in vitro. Four species, including Rubifructus, Cornifructus, Salicis radicis cortex, and Geranium nepalense, were the most potent lipase inhibitors, exhibiting at least 30\% inhibition. The anti-obesity effect of the extracts was further confirmed by their ability to reduce lipid uptake in 3T3-L1 adipocytes [26].

Very few studies attempted to study the inhibition of LPL by plants extracts. Moreno et al. assessed the effect of grape seed extract and peanut nutshell extract in vitro, showing an average inhibition of $30 \%$ at $1 \mathrm{mg} /$ $\mathrm{mL}$ [25]. The inhibition potential was attributed to a synergistic effect of various plant bioactives, especially polyphenols. An ethanolic extract of $M$. citrifolia fruit extract was reported to inhibit LPL activity by $21.5 \pm 2.3 \%$ [13], which is higher than the inhibition achieved by leaf extracts shown in this study. Extracts with lower concentration of ethanol (60-40\%) showed significantly higher inhibition $(p<0.05)$ compared to leaves extracted with pure ethanol.

Based on their TPC, DPPH scavenging activity, and lipase inhibiting potential, mature leaf extracted with $60 \%$ ethanol, defined as MLE60, was selected for further analysis using ${ }^{1} \mathrm{H}$ NMR and $2 \mathrm{D}^{1} \mathrm{H}-{ }^{1} \mathrm{H}$ NMR and LCMS/HPLC for identification and quantification of metabolites, respectively.

\section{${ }^{1} \mathrm{H}$ NMR spectra and assignments of compounds in MLE60}

Certain metabolites were discernible in MLE60 as analysed by ${ }^{1} \mathrm{H}$ NMR. Due to overlapping of peaks, $J$ - resolve 
and heteronuclear multiple-bond correlation spectroscopy (HMBC) were used to gather more information on signal splitting and the coupling constant for the confirmation of compounds with those reported in literature (Figure 1). A list of identified compounds is given in Table 3. Among the important compounds are catechin, kaempherol and rutin, which are three flavonoids reported to have anti-obesity effects. These compounds together with other flavonoids like quercetin have been identified in the leaves of $M$. citrifolia previously [27]. Rutin has been reported to have anti-obesity effect in many in vitro and in vivo studies [28]. LCMS identification and HPLC quantification of commonly present flavonoids in plants in MLE60 revealed the presence of rutin as the predominant compound among the flavonoids tested. MLE60 contained $16.46 \pm 0.91 \mathrm{mg}$ of rutin/g of dried plant extract. In relation to obesity, in vivo, intervention with 50 and $100 \mathrm{mg}$ rutin/ $\mathrm{kg}$ body weight resulted in prevention of weight gain in HFD-induced obese Wistar rats [29]. Based on the preliminary findings, MLE60 was assessed for prevention of HFD-induced obesity in Sprague- Dawley rats.
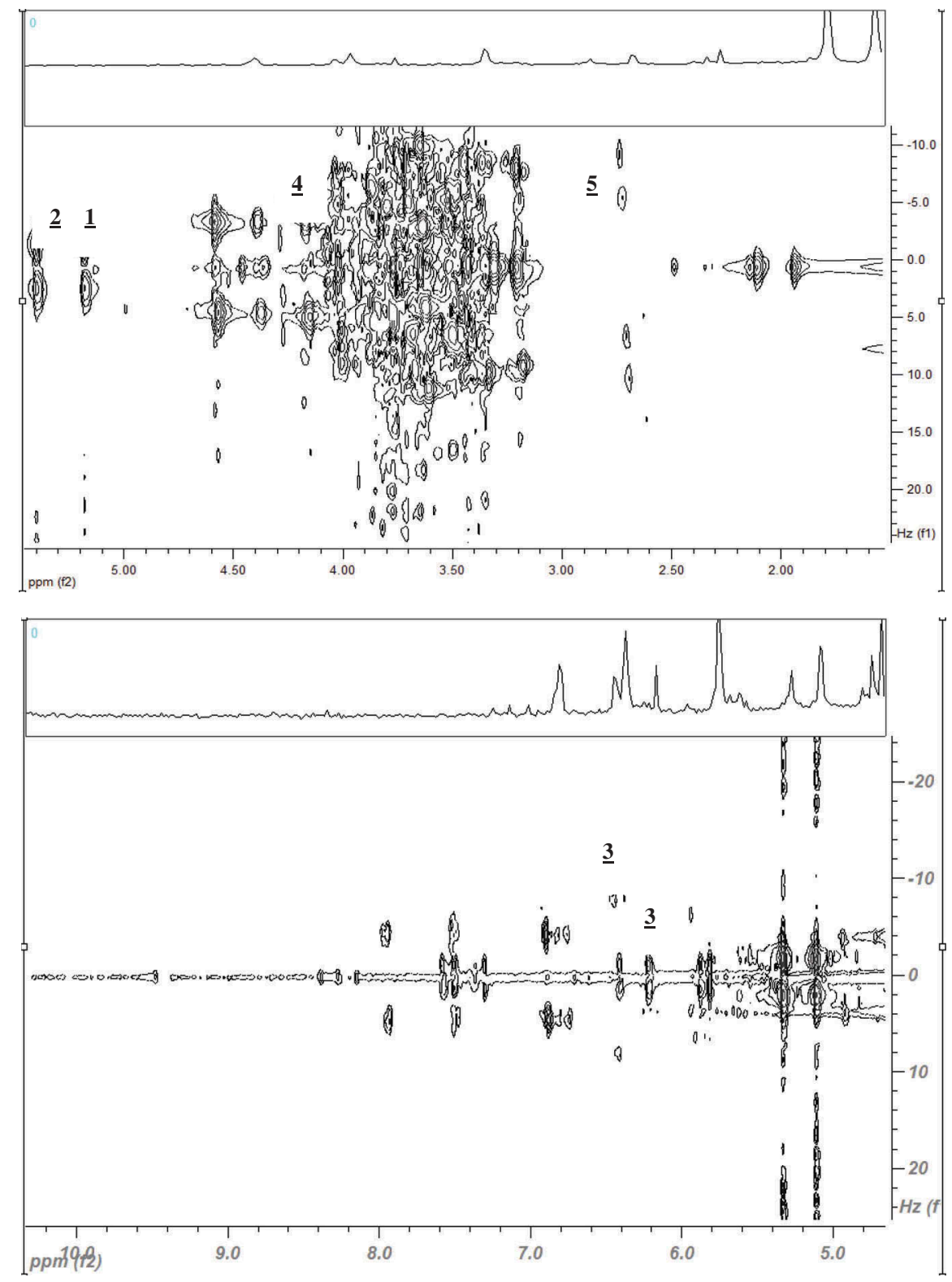

Figure 1. ${ }^{1} \mathrm{H}-{ }^{1} \mathrm{H}$ J-resolved spectra of $M$. citrifolia mature leaves extracted with $60 \%$ of ethanol and $40 \%$ water (MLE60) in the region of $\delta 2.0$ to 8.0 The observed signals are defined as [1] a-glucose, [2] sucrose, [3] kaempherol derivatives, [4] rutin derivatives, and [5] catechin derivatives. 
Table 3. Chemical shifts assignments of characteristics ${ }^{1} \mathrm{H}$ NMR signals of some metabolites in $M$. citrifolia extract (MLE60).

\begin{tabular}{lc}
\hline Metabolite & ${ }^{1} \mathrm{H}$ NMR characteristics \\
\hline B-Glucose & $4.59(d, J=7.5 \mathrm{~Hz})$ \\
a-Glucose & $5.19(d, J=3.5 \mathrm{~Hz})$ \\
Sucrose & $5.41(d, J=4 \mathrm{~Hz})$ \\
Rutin & $6.22(d, J=2.0 \mathrm{~Hz})$ \\
& $6.39(d, J=2.0 \mathrm{~Hz})$ \\
& $7.47(d, J=2.0 \mathrm{~Hz})$ \\
& $6.90(d, J=8.5 \mathrm{~Hz})$ \\
Kaempherol-3-O-a-L-rhamnopyranosyl-[1-6]-B-D-glucopyranoside & $7.56(d d, J=2.0,8.5)$ \\
& anomeric proton glucosyl $4.95(d, J=8.0)$ \\
& rhamnosyl $4.58(d, J=1.0)$ \\
& $8.07(d, J=8.8 \mathrm{~Hz})$ \\
& $6.90(d, J=8.8 \mathrm{~Hz})$ \\
Catechin & $6.40(d, J=1.8 \mathrm{~Hz})$ \\
& $6.21(d, J=1.8 \mathrm{~Hz})$ \\
& $5.15(d, J=7.6 \mathrm{~Hz})$ \\
& $4.54(s)$ \\
& $3.20-3.90(\mathrm{~m})$ \\
& $1.14(d, J=5.8 \mathrm{~Hz})$ \\
& $6.47(d, J=2.0 \mathrm{~Hz})$ \\
& $4.57(d, J=7.5 \mathrm{~Hz})$ \\
& $6.50(d, J=2.0 \mathrm{~Hz})$ \\
& $2.56(d d, J=7.5,16 \mathrm{~Hz})$ \\
& $3.98(\mathrm{~m})$ \\
\hline
\end{tabular}

$s:$ singlet, $d$ : doublet, $t$ : triplet, $d d$ : doublet of doublets, $m$ : multiplet

\section{Effect of MLE60 on body weight, food intake and faecal fat excretion}

Excessive calorie intake contributes to the development of obesity. The preventive effect of MLE60 on weight gain, appetite and faecal fat excretion in lean male Sprague-Dawley rats were investigated. This study confirms other findings that Sprague-Dawley rats fed an HFD for a long period of time, develop obesity, with a predominant accumulation of visceral fat as compared to rats on normal rat chow [30]. Usually, researchers opt for a higher percentage of fat $(60 \%)$ so as to induce obesity in as little as 6 weeks [9]. If extrapolated to the human diet, a $60 \%$ fat content might not be realistic. Therefore the present study which uses a HFD with $36 \%$ of total energy from coconut fat is in line with recent studies which used HFDs with a reduced fat content (36-40\%) with a longer time to induce obesity [31]. Rats on the HFD showed a $172 \%$ increase of their initial body weight after 12 weeks, while supplementation with MLE60 reduced weight gain. Rats receiving 150 and $350 \mathrm{mg} / \mathrm{kg}$ of MLE60 together with the HFD, showed no significant difference $(p<0.05)$ in weight gain as compared to rats receiving the ND (Figure 2). In terms of food intake, rats on the ND $(3.27 \mathrm{kcal} / \mathrm{g})$ consumed more in terms of volume as compared to the HFD but have lesser weight gain, thus confirming the higher calorie intake in the HFD group $(4.39 \mathrm{kcal} / \mathrm{g}$ ). The supplementation of MLE60 did not affect food intake in the HFD group, indicating that appetite suppression might not be the main anti-obesity mechanism involved (Table 4). Specifically to M. citrifolia, Mandukhail et al. reported prevention in weight gain in rats fed a HFD to induce hyperlipidaemia [14]. However, a reduction of food intake of rats fed extracts of the fruits and leaves were also reported. This can be attributed to the high dosage used $(1000 \mathrm{mg} / \mathrm{kg}$ body weight), which could have affected the palatability of the diet.

The difference in weight gain among the different groups is clearly demonstrated by the percentage of visceral fat depot, where rats on the HFD plus MLE60 had significantly $(p<0.05)$ reduced percentage of visceral fat (3.45-4.04\%) as compared to rats on the HFD only $(6.08 \%)$ (Table 4$)$. The results of this study are quite similar to those reported by Yamamoto et al. whereby weight gain was observed in lean rats fed a HFD with and without the administration of CT-II extract [32]. Lean rats receiving $2.5 \%$ of the extract had a suppressed weight gain during the 8 weeks of treatment, with a reduced percentage of parametrial fat. This effect was most likely to be mediated by an inhibition of digestive lipases. Similarly, the anti-obesity effects of $G$. thundergii extract in HFD-induced obese mice was investigated. Supplementation with the extracts for 6.5 weeks decreased body weight, adipose tissue mass, with a general amelioration in the serum lipid, leptin, and adiponectin profile [33].

Based on previous studies [34], it is postulated that MLE60 could have an anti-obesity effect through the inhibition of metabolic and digestive lipases, 


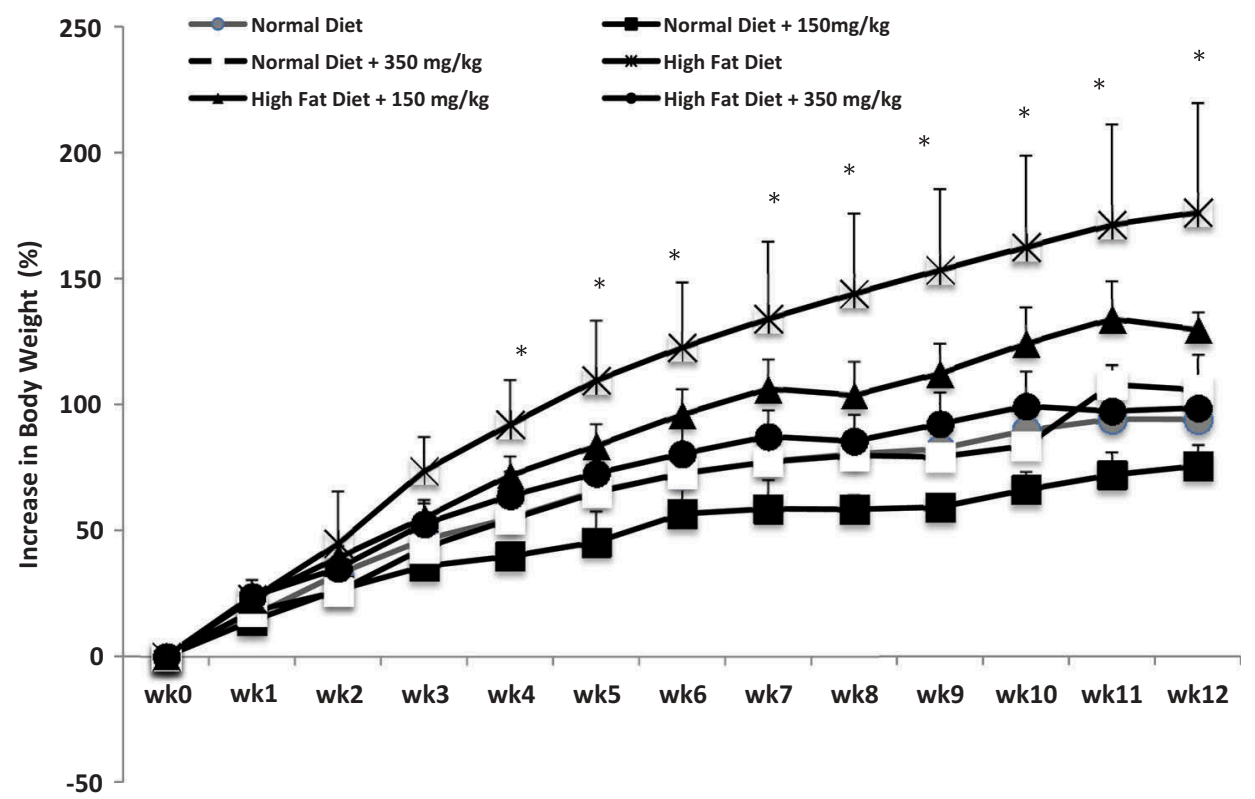

Figure 2. Percentage weight gain of rats fed a normal diet (ND) or a high fat diet (HFD) with our without the supplementation of $150 \mathrm{mg} / \mathrm{kg}$ body weight MLE60 or $350 \mathrm{mg} / \mathrm{kg}$ body weight MLE60.

Values with * indicate significant difference $(p<0.05)$ in weight gain between different groups, during the same week of the experiment. All statistical analysis was carried out using one way ANOVA MINITAB version 14.

mimicking a reduced calorie intake. The faecal fat content was assessed as an indication of enzymes inhibition. The faecal fat content of rats in the HFD+150 (14.72, 11.37\%) and HFD+350 (16.073, 19.58\%) seem to support this hypothesis, as in both week 6 and week 12 of the study, rats receiving MLE60 had higher faecal fat content as compared to the control (Table 4). This suggests an inhibition of lipase by MLE60 in vivo. This is in line with previous studies showing that anti-obesity agents such as green tea increase energy content of faces in rats [35] and catechins from green tea showed increased faecal excretion of energy nutrients through the inhibition of digestive enzymes [36]. Potent lipase inhibitor, CT-II from Nomame Herba, resulted in significantly higher steatorrhea as compared to rats in the HFD group [32]. There was no indication of diarrhoea

Table 4. The daily food intake, visceral fat content, faecal fat excretion, plasma lipids, glucose, insulin, leptin, adiponectin, ghrelin, and toxicity markers levels in rats fed a normal diet (ND) or a high fat diet (HFD) after 12 weeks of supplementation with or without MLE60 at $150 \mathrm{mg} / \mathrm{kg}$ or $350 \mathrm{mg} / \mathrm{kg}$ body weight.

\begin{tabular}{|c|c|c|c|c|c|c|}
\hline & HFD & $\mathrm{HFD}+150$ & $\mathrm{HFD}+350$ & ND & $N D+150$ & $N D+350$ \\
\hline Daily food intake ( $\mathrm{g} / \mathrm{rat} /$ day) & $16.45 \pm 2.60^{c}$ & $15.38 \pm 4.10^{c}$ & $14.54 \pm 2.60^{c}$ & $21.98 \pm 1.80^{\mathrm{a}}$ & $18.77 \pm 2.00^{b}$ & $20.28 \pm 1.70^{\mathrm{ab}}$ \\
\hline Visceral fat (\%) & $6.98 \pm 0.63^{c}$ & $4.04 \pm 0.80^{b}$ & $4.45 \pm 0.96^{b}$ & $2.07 \pm 0.58^{\mathrm{a}}$ & $1.40 \pm 0.49^{a}$ & $1.97 \pm 0.28^{\mathrm{a}}$ \\
\hline Faecal fat content (\%) & $4.40 \pm 0.82^{\mathrm{aA}}$ & $14.73 \pm 1.68^{\mathrm{aB}}$ & $16.07 \pm 2.81^{\mathrm{aB}}$ & $3.28 \pm 0.34^{\mathrm{aA}}$ & $2.80 \pm 0.27^{\mathrm{aA}}$ & $5.07 \pm 0.34^{\mathrm{aA}}$ \\
\hline Middle (Week 6) & $5.34 \pm 0.62^{\mathrm{aB}}$ & $11.37 \pm 0.56^{\mathrm{aB}}$ & $19.58 \pm 3.36^{\mathrm{aA}}$ & $6.43 \pm 1.76^{\mathrm{aB}}$ & $10.67 \pm 1.04^{\mathrm{bB}}$ & $10.42 \pm 0.76^{\mathrm{bB}}$ \\
\hline \multicolumn{7}{|l|}{ Final (Week 12) } \\
\hline Total cholesterol (mmol/L) & $1.28 \pm 0.05^{c}$ & $0.86 \pm 0.05^{a}$ & $0.95 \pm 0.19^{a}$ & $1.36 \pm 0.17^{b}$ & $1.26 \pm 0.14^{\mathrm{bc}}$ & $1.35 \pm 0.05^{b c}$ \\
\hline $\mathrm{HDL}(\mathrm{mmol} / \mathrm{L})$ & $0.63 \pm 0.10^{b}$ & $0.65 \pm 0.08^{b}$ & $0.72 \pm 0.05^{\mathrm{ab}}$ & $1.03 \pm 0.16^{a}$ & $0.90 \pm 0.11^{\mathrm{a}}$ & $1.00 \pm 0.04^{\mathrm{a}}$ \\
\hline $\mathrm{LDL}(\mathrm{mmol} / \mathrm{L})$ & $0.25 \pm 0.04^{b}$ & $0.14 \pm 0.02^{a}$ & $0.13 \pm 0.02^{\mathrm{a}}$ & $0.29 \pm 0.05^{b}$ & $0.30 \pm 0.04^{b}$ & $0.30 \pm 0.03^{b}$ \\
\hline Triglycerides (mmol/L) & $1.01 \pm 0.05^{c}$ & $0.36 \pm 0.11^{\mathrm{ab}}$ & $0.51 \pm 0.06^{\mathrm{b}}$ & $0.25 \pm 0.06^{a}$ & $0.29 \pm 0.04^{a}$ & $0.24 \pm 0.02^{a}$ \\
\hline Glucose (mmol/L) & $6.48 \pm 0.76^{b}$ & $6.20 \pm 1.19^{b}$ & $6.15 \pm 0.81^{\mathrm{b}}$ & $4.80 \pm 0.16^{a}$ & $5.03 \pm 0.60^{\mathrm{ab}}$ & $5.08 \pm 0.01^{\mathrm{ab}}$ \\
\hline Insulin $(\mu \mathrm{g} / \mathrm{L})$ & $0.72 \pm 0.08^{d}$ & $0.46 \pm 0.06^{c}$ & $0.34 \pm 0.05^{\mathrm{b}}$ & $0.22 \pm 0.01^{a}$ & $0.18 \pm 0.01^{\mathrm{a}}$ & $0.14 \pm 0.01^{a}$ \\
\hline Leptin $(\mathrm{pg} / \mathrm{mL})$ & $1948.9 \pm 46.7^{d}$ & $1627.3 \pm 216.3^{c}$ & $935.6 \pm 140.3^{b}$ & $535.3 \pm 12.9^{\mathrm{a}}$ & $556.7 \pm 18.6^{a}$ & $377.8 \pm 40.2^{a}$ \\
\hline Adiponectin (ng/mL) & $13.39 \pm 2.00^{\mathrm{a}}$ & $13.99 \pm 1.71^{\mathrm{a}}$ & $15.39 \pm 2.81^{\mathrm{a}}$ & $16.39 \pm 2.28^{\mathrm{a}}$ & $18.13 \pm 5.61^{a}$ & $14.09 \pm 0.45^{\mathrm{a}}$ \\
\hline Ghrelin (ng/mL) & $30.08 \pm 7.78^{b}$ & $61.61 \pm 8.84^{a}$ & $30.40 \pm 8.61^{b}$ & $61.31 \pm 1.07^{\mathrm{a}}$ & $52.68 \pm 8.42^{a}$ & $61.32 \pm 1.53^{a}$ \\
\hline Creatinine $(\mu \mathrm{mol} / \mathrm{L})$ & $53.00 \pm 2.94^{\mathrm{a}}$ & $53.00 \pm 3.56^{a}$ & $54.00 \pm 3.56^{a}$ & $54.75 \pm 2.22^{\mathrm{a}}$ & $55.25 \pm 2.36^{\mathrm{a}}$ & $60.75 \pm 1.89^{a}$ \\
\hline Urea (mmol/L) & $3.36 \pm 0.05^{\mathrm{a}}$ & $3.16 \pm 0.45^{\mathrm{a}}$ & $5.05 \pm 0.17^{b}$ & $5.70 \pm 0.22^{c}$ & $6.45 \pm 0.46^{c}$ & $6.10 \pm 0.96^{b c}$ \\
\hline GGT (U/L) & $6.00 \pm 2.16^{c}$ & $2.00 \pm 1.15^{\mathrm{ab}}$ & $3.50 \pm 0.57^{b}$ & $1.00 \pm 0.00^{a}$ & $1.00 \pm 0.00^{a}$ & $1.00 \pm 0.00^{\mathrm{a}}$ \\
\hline AST (U/L) & $94.63 \pm 1.90^{\mathrm{a}}$ & $92.55 \pm 2.70^{\mathrm{a}}$ & $88.80 \pm 2.89^{a}$ & $90.35 \pm 6.27^{\mathrm{a}}$ & $99.95 \pm 19.91^{\mathrm{a}}$ & $104.13 \pm 18.09^{a}$ \\
\hline ALT $(U / L)$ & $32.15 \pm 3.28^{a}$ & $32.53 \pm 5.45^{\mathrm{a}}$ & $32.63 \pm 5.24^{a}$ & $34.48 \pm 2.29^{a}$ & $44.23 \pm 5.49^{b}$ & $37.08 \pm 2.58^{\mathrm{a}}$ \\
\hline ALP (U/L) & $149.25 \pm 15.52^{c}$ & $114.50 \pm 17.60^{b}$ & $114.00 \pm 5.77^{b}$ & $70.75 \pm 5.32^{\mathrm{a}}$ & $90.25 \pm 6.90^{\mathrm{ab}}$ & $97.00 \pm 14.51^{a b}$ \\
\hline
\end{tabular}

Different small letters indicate significance difference $(p<0.05)$ between different groups and difference in big letters indicate significance difference in the same group at different time points as shown by the analysis of variance (ANOVA) using MINITAB VERSION 14. 
and abnormal lipid biochemistry in the subjects, suggesting that MLE60 has lesser side effects as opposed to Orlistat $^{\varpi}$, where abdominal discomfort and diarrhoea has been reported in humans [37].

Rutin and kaempherol were among the predominant flavonoids present in MLE60. These compounds together with other flavonoids like quercetin have been identified in the leaves of $M$. citrifolia previously [27]. Rutin was found to be the most potent in suppressing 3T3-L1 cell differentiation, in a dose dependent manner. At the induction stage of adipogenesis, rutin suppressed the activity of glycerol-3-phosphate dehydrogenase and activity of adipogenic factors such as peroxisome proliferator-activated receptor- $\gamma$ (PPAR$\gamma)$ and CCAAT/enhancer binding protein- $\alpha(\mathrm{C} / \mathrm{EBP} \alpha)$ in 3T3-L1 cells. In vivo, supplementation of rutin (25 mg and $50 \mathrm{mg} / \mathrm{kg}$ body weight) for 4 weeks in C57BL/6 mice fed a HFD resulted in reduced weight gain as compared to mice fed the HFD only. The antiobesity effect of rutin was most likely to be mediated by the down regulation of certain adipogenic transcription factors as reflected by the down regulation of PPAR- $\gamma$ and C/EBPa mRNA [38]. In obese Wistar rats, a 8 weeks intervention with 50 and $100 \mathrm{mg}$ rutin $/ \mathrm{kg}$ body weight, reduced body weight and adipose tissue, with amelioration in the serum lipid profiles, insulin, leptin, TG, cholesterol level, and oxidative profiles, confirming the protective effect of rutin in HFD induced dyslipidaemia, hepatosteatosis, and oxidative stress [29].

\section{Effect of MLE60 on plasma biochemistry}

Apart from increased weight and fat accumulation, obesity is associated with other physiological disruptions, which is reflected by changes in the plasma biochemistry. A number of plasma components were measured in the treated and untreated HFD group and compared with the plasma profiles of rats fed the ND.

In general, MLE60 positively influenced the lipid profiles in the treatment group receiving the HFD (Table 4). The effect of purified HFD on TC is inconsistent though in most cases, hypercholesterolemia is not induced by diet only but with the addition of cholesterol. Only in the case of a fish fat based HFD, hypocholesterolaemia is induced [30]. A reduction in LDL level was recorded in both treated groups. Phenolic compounds such as rutin have been reported to positively modulate cholesterol metabolism. Rats receiving $1 \mathrm{~g}$ of cholesterol/kg for 5 weeks had lower plasma lipids and hepatic cholesterol with supplementation of rutin $(1 \mathrm{~g} / \mathrm{kg}$ body weight). The cholesterol lowering potential was mediated through the inhibition of HMG-CoA reductase and ACAT activity and an increased faecal sterol excretion. The study also reported the protective effect of rutin and tannic acid against oxidative stress [39].

Both a low dose $(50 \mathrm{mg} / \mathrm{kg})$ and a high dose of rutin $(100 \mathrm{mg} / \mathrm{kg})$ in rats fed a HFD containing $40 \%$ fat from beef tallow resulted in an improvement in the lipids profile in a dose dependent manner. LDL cholesterol and TC levels were reduced in the treated groups, without any changes in the HDL [29].

The HFD only group had significant higher plasma insulin levels $(0.72 \pm 0.07 \mu \mathrm{g} / \mathrm{L})$ as compared to rats receiving the ND only $(0.215 \pm 0.01 \mu \mathrm{g} / \mathrm{L})$ (Table 3$)$. Administration of MLE60 improved plasma insulin dose dependently, with rats receiving $350 \mathrm{mg} / \mathrm{kg}$ body weight having the most improved profile $(0.34 \pm 0.05 \mu \mathrm{g} / \mathrm{L})$, followed by rats receiving $150 \mathrm{mg} /$ $\mathrm{kg}$ body weight $(0.46 \pm 0.06 \mu \mathrm{g} / \mathrm{L})$. Various studies report an increase in plasma glucose and insulin levels with the administration of a HFD [40]. The insulin level was found to be increased 3.6 folds in the group receiving the HFD as compared to rats on the ND. Groups receiving the HFD together with different doses of MLE had improved insulin level, though not same as the normal rats. This might have been the causative effect of decreased visceral fats in the groups receiving the HFD together MLE60, whereby the visceral fat though reduced, was not comparable to the rats receiving the ND. Insulin insensitivity has been long been associated with an increase in visceral adiposity. People suffering from visceral obesity have a higher chance of having impaired insulin sensitivity and targeted weight loss in the visceral area can ameliorate insulin sensitivity [41].

Similar trend has been reported by Kishino et al. whereby insulin level was increased four times in female mice receiving a HFD as compared to mice on the ND [42]. Feeding of a mixture of $S$. reticulata aqueous extract and cyclodextrin $(0.2 \%$ and $0.5 \%)$ resulted in an improvement of the insulin levels. This effect was attributed to the secondary modulation of metabolism associated with reduced visceral fat.

Leptin plays a predominant role in regulating food intake and energy expenditure, depending on the body fat content. People having a higher BMI have high serum and plasma leptin concentration. As opposed to insulin sensitivity, which improves with decrease in visceral fat, leptin can exert long acting effect to reduce adiposity [43].

In this study, the level of leptin was markedly reduced in the group receiving the HFD together with MLE60: the highest administered dosage of $350 \mathrm{mg} / \mathrm{kg}$ resulted in a twofold reduction $(935.6 \mathrm{pg} / \mathrm{mL})$ 
comparable to the control normal group $(535.3 \mathrm{pg} / \mathrm{mL})$ (Table 4). Other plant extracts associated with antiobesity effects have improved plasma leptin profiles in subjects fed an HFD. Administration of various dosages of Yerba Mate (I. paraguariensis) in C57BL/6J mice resulted in a three times reduction of leptin concentration as compared to the control group. The extract showed both anti-obesity and anti-diabetic effect in vivo [9].

Circulating leptin levels is proportional to general adiposity and reduced adipose fat can result in decrease leptin concentrations [44]. Based on the fact that leptin in an appetite regulating hormone, it is expected to affect the appetite of rats in the groups having improved leptin levels. However, no changes were observed in food intake of rats within the groups receiving the same diets. Hayamizu et al. reported similar findings for the leptin lowering effect of $G$. cambogia extracts in mice fed a HFD [45]. In their study also, there was a direct correlation between leptin concentration and adiposity. It is proposed that this effect was through a leptin like activity of the extract, based on the relation between insulin and leptin.

Results from the present study also tend to show similar trends in the plasma concentration of leptin and insulin. The presence of leptin receptors on pancreatic $\beta$-cells has suggested possible involvement of leptin in insulin secretion [46]. This was further confirmed when a physiological increase in plasma leptin inhibited insulin secretion in vivo, in a dose dependent manner, independent of the cAMP phosphodiesterase 3 inhibitor [47].

Adiponectin, a hormone secreted by adipocytes has been shown to improve insulin resistance by decreasing the triglycerides content in muscles and liver of obese rodents. Its insulin sensitising properties include the suppression of hepatic glucose production and enhancing glucose uptake by the skeletal muscles [48]. In human subjects, plasma concentration of adiponectin is correlated with insulin sensitivity [49].

Similar to the effects in humans, the adiponectin levels in leptin-deficient, spontaneously obese mice were lower in obese mice than in lean mice. An extract of green tea did not ameliorate the adiponectin level in the HFD group [50]. On the contrary, Kishino et al. reported a significant decrease in the adiponectin levels of rats receiving a HFD with an extract of K. himbutu as compared to rats receiving the HFD only [42]. Some studies reported adiponectin levels to be unchanged in mice fed a HFD for 12 weeks in both the control and the treatment group [31]. This has been comprehensively studied by Barnea et al., who reported to the unchanged levels of adiponectin in mice fed an HFD, by no yet elucidated mechanisms of protection in rodents against decreased level of adiponectin [51].

Findings from this study showed no significant difference in adiponectin levels in all groups (13.39$18.12 \mathrm{ng} / \mathrm{mL}$ ), though the level of adiponectin in obese rats was the lowest $(13.39 \mathrm{ng} / \mathrm{mL})$. Inter-individual variability might be one of the reasons of nonsignificance, since the trends in leptin and insulin levels suggest otherwise.

Rats on the HFD only had the lowest plasma ghrelin level $(30.075 \mathrm{ng} / \mathrm{mL})$, which was restored to the normal levels $(61.311 \mathrm{ng} / \mathrm{mL})$ by supplementation of MLE60 at the dosage of $150 \mathrm{mg} / \mathrm{kg}(66.613 \mathrm{ng} / \mathrm{mL})$. A higher dose of MLE60 at $250 \mathrm{mg} / \mathrm{kg}$ did not improve plasma ghrelin levels. Ghrelin levels are generally decreased in human obesity and at meal times. It has also been proposed that ghrelin receptor can be good targets for anti-obesity drug, through appetite suppression [52]. In this study, the levels of ghrelin in HFD fed rats treated with MLE60 were improved even though no significant difference in food intake. Similarly, a water-alcohol naringin rich extract of $C$. grandis improved ghrelin levels in obese Zucker rats [53].

The overall kidney function is measured by the glomerular filtration rate (GFR), which cannot be assessed directly. Filtration markers such as creatinine and urea are used as renal function indicators, clinically [54]. In this study, the creatinine levels among the various groups were not significantly different, in both rats fed the HFD $(53.00 \mu \mathrm{mol} / \mathrm{L})$ or the ND $(54.75 \mu \mathrm{mol} / \mathrm{L})$. Results are consistent with various studies reporting unchanged levels of creatinine in obese subjects as there is no change is muscle mass [55].

The blood urea nitrogen (BUN) was also measured as indicator of renal function. Rats fed a HFD and HFD +150 had significantly lower urea content as compared to rats fed the ND. The higher dosage of MLE60 $(350 \mathrm{mg} / \mathrm{kg}$ ) improved the urea levels in the treated group. Consistent with findings from this study, blood urea level has been previously reported to be decreased in obese rats, irrespective of whether being fed a palatable cafeteria diet or a standard chow. This suggests that decreased urea level was related to the condition of obesity rather than the diet [56].

In the current study, four markers of liver function were measured (GGT, ALP, AST, and ALT). Significant changes were only observed in the GGT and ALP levels. Obese rats had significantly higher ALP (149.25 U/L) and GGT (6.0 U/L) levels than their lean counterparts, with 70.75 and $1.0 \mathrm{U} / \mathrm{L}$, respectively. 
Table 5. Weight of organs (g).

\begin{tabular}{lccccc}
\hline Group & Liver & Kidney & Heart & Lung & Testis \\
\hline HFD & $9.05 \pm 1.23^{\mathrm{a}}$ & $2.27 \pm 0.26^{\mathrm{a}}$ & $1.24 \pm 0.8^{\mathrm{a}}$ & $1.46 \pm 0.28^{\mathrm{a}}$ & $1.24 \pm 0.41^{\mathrm{b}}$ \\
HFD+350 & $8.06 \pm 1.46^{\mathrm{ab}}$ & $2.04 \pm 0.16^{\mathrm{ab}}$ & $1.22 \pm 0.14^{\mathrm{a}}$ & $1.49 \pm 0.25^{\mathrm{a}}$ & $1.48 \pm 0.17^{\mathrm{ab}}$ \\
HFD+150 & $8.99 \pm 0.85^{\mathrm{ab}}$ & $2.14 \pm 0.2^{\mathrm{ab}}$ & $1.23 \pm 0.14^{\mathrm{a}}$ & $2.01 \pm 0.87^{\mathrm{a}}$ & $1.48 \pm 0.14^{\mathrm{ab}}$ \\
ND & $9.11 \pm 1.82^{\mathrm{ab}}$ & $2.44 \pm 0.42^{\mathrm{a}}$ & $1.21 \pm 0.20^{\mathrm{a}}$ & $1.49 \pm 0.30^{\mathrm{a}}$ & $1.69 \pm 0.31^{\mathrm{a}}$ \\
ND+150 & $6.88 \pm 0.42^{\mathrm{b}}$ & $1.83 \pm 0.08^{\mathrm{b}}$ & $0.94 \pm 0.15^{\mathrm{a}}$ & $1.38 \pm 0.13^{\mathrm{a}}$ & $1.47 \pm 0.13^{\mathrm{ab}}$ \\
ND+350 & $7.63 \pm 0.77^{\mathrm{ab}}$ & $2.26 \pm 0.28^{\mathrm{ab}}$ & $1.20 \pm 0.08^{\mathrm{a}}$ & $1.50 \pm 0.05^{\mathrm{a}}$ & $1.70 \pm 0.08^{\mathrm{a}}$ \\
\hline
\end{tabular}

Different letters indicate significance difference $(p<0.05)$ of the same organ between different groups as shown by the analysis of variance (ANOVA) using MINITAB version 14.

Administration of MLE60 at various doses improved the GGT and ALP levels in rats fed a HFD and did not cause significant changes in rats fed a ND.

Green tea extract reduced hepatic liver injury, as reflected by decreased levels of ALT and AST. This effect was attributed to the lipid lowering potential of the green tea extract [50]. In a similar study, serum AST, ALP and ALT were increased in rats fed a HFD. Groups supplemented with raspberry ketone had lower levels of enzymes. The attenuation of steatohepatitis was attributed to decreased liver inflammation, improvement of dyslipidaemia, and increased sensitivity to leptin and insulin [57].

As a preliminary indicator of toxicity, the weight of all organs was recorded upon sacrifice. No significant findings were recorded, especially in the treated group, suggesting that MLE60 was not toxic at the administered dosages (Table 5). Moreover, M. citrifolia is well known for its history of safe use and no perceived toxicity across the world, except some isolated cases due to the extreme consumption of noni juice [16]. Testing of $M$. citrifolia did not show any sign of toxicity in rats [58] and $\mathrm{LD}_{50}$ values of $7500 \mathrm{mg} / \mathrm{kg}$ and $3500 \mathrm{mg} / \mathrm{kg}$ were determined for the aqueous and ethanol extracts, respectively [59]. In this study, a maximum dosage of $350 \mathrm{mg} / \mathrm{kg}$ of ethanolic extract was used, an equivalent of $1 \mathrm{~g}$ of powdered leaves. However, more profound toxicology studies are required in the event that MLE60 is further advised to be used for preventing weight gain.

\section{Conclusion}

Rats receiving the HFD together with MLE60 had reduced weight gain as compared to rats receiving the HFD only. The weight gain in the treated groups was not significantly different to weight gain by rats fed a ND. Daily food intake did not differ between the treated and control groups, therefore eliminating appetite suppression as one of the potential anti-obesity mechanism. Increased faecal fat excretion at week 6 and week 12 reinforces the initial hypothesis of lipase inhibition by MLE60. The plasma lipid profiles were also improved, with a marked decrease in plasma TG and LDL levels. Other pro-obesity related factors such as plasma insulin and leptin were significantly improved, suggesting that in addition to its lipase inhibitory effects; MLE60 positively modulates adipocytic mechanisms through a leptin like activity, to exhibit anti-obesity properties. Supplementation of the extract at the prescribed dosages did not adversely affect liver and kidney toxicity markers. No abnormal bowel activities (no oily stools, no diarrhoea) were recorded in the treated group, as it is the case with the commonly prescribed anti-obesity drug, pancreatic lipase inhibitor, Orlistat ${ }^{\circledast}$ at the required dosage of $120 \mathrm{mg}$, three times a day. However, more advanced toxicity studies are required for conclusive results.

MLE60 shows promise as a natural and safe antiobesity agent and warrants further investigation. In this study, the effect of the extract was assessed in lean rats fed a HFD, to mimic the current trend of high caloric environment and possible prevention of obesity in lean subjects. It would be interesting to study the effect of the same extract on HFD induced obese models, to verify whether MLE60 can be curative, as well as preventive.

\section{Acknowledgments}

The authors would like to acknowledge the Ministry of Science, Technology and Innovation (MOSTI) of Malaysia and Agro-Biotechnology Institute of Malaysia for financing the project. The authors would also like to acknowledge Functional Foods Laboratory, Universiti Putra Malaysia for the facilities provided.

\section{Conflicts of Interest}

The authors declare no conflict of interest.

\section{Disclosure statement}

No potential conflict of interest was reported by the authors. 


\section{References}

[1] WHO. Expert consultation on waist circumference and waist hip ratio. 8-11 December. Geneva, Switzerland: WHO; 2008.www.who.int/nutrition/publication/obesity/ WHO_report_waistcircumference_and_waisthip_ratio/en/

[2] Keaney JF, Larson MG, Vasan RS. Obesity and systemic oxidative stress: clinical correlates of oxidative stress in the Framingham study. Arterioscler Thromb Vasc Biol. 2003;23:434-439.

[3] Higdon JV, Frei B. Obesity and oxidative stress- a direct link to CVD? Arterioscler Thromb Vasc Biol. 2003;23:365-367.

[4] Anuar Zaini ZA, Lim CT, Low WY, et al. Factors affecting nutritional status of Malaysian primary school children. Asia Pac Journal Public Health. 2005;17:271280.

[5] Finkelstein EA, Kharjou OA, Thompson $\mathrm{H}$, et al. Obesity and severe obesity forecasts through 2030. Am J Prev Med. 2012;42:563-570.

[6] Bays H, Dujovne C. Anti-obesity drug development. Expert Opin Investig Drugs. 2002;11:1189-1204.

[7] Gooda Sahib N, Abdul Hamid A, Saari N, et al. Antipancreatic lipase and antioxidant activity of selected tropical herbs. Int J Food Prop. 2012a;15:569-578.

[8] Yun JW. Possible anti-obesity therapeutic from naturea review. Phytochem. 2010;71:1625-1641.

[9] Kang YR, Lee HY, Kim JH, et al. Anti obesity and anti diabetic effects of Yerba Mate (Ilex paraguariensis) in C57BL/6J mice fed a high fat diet. Lab Anim Res. 2012;28:23-29.

[10] Xu Y, Zhang M, Wu T, et al. The anti-obesity effect of green tea polysaccharides, polyphenols and caffeine in rats fed with a high-fat diet. Food Funct. 2015;6:297-304.

[11] Mopuri R, Ganjayi M, Banavathy KS, et al. Evaluation of anti-obesity activities of ethanolic extract of Terminalia paniculata bark on high fat diet-induced obese rats. BMC Complement Altern Med. 2015;15:1-11.

[12] Bais S, Singh GS, Sharma R. Antiobesity and hypolipidemic activity of moringa oleifera leaves against high fat diet-induced obesity in rats. Adv Biol. 2014;2014:1-9.

[13] Gooda Sahib N, Abdul Hamid A, Kitts D, et al. The effects of Morinda citrifolia, Momordica charantia and Centella asiatica extracts on lipoprotein lipase and 3T3L1 preadipocytes. J Food Biochem. 2011;35:1186-1205.

[14] Mandukhail SUR, Aziz N, Gilani AH. Studies on the antidyslipidemic effects of Morinda citrifolia (noni) fruits, leaves and roots extracts. Lipids Health Dis. 2010;9:1-6.

[15] Mohd Zin ZM, Abdul-Hamid A, Osman A. Antioxidative activity of extracts from Mengkudu (Morinda citrifolia L.) root, fruit and leaf. Food Chem. 2002;78:227-231.

[16] Pawlus AD, Kinghorn AD. Review of ethnobotany, chemistry, biological activity and safety of the botanical dietary supplement Morinda citrifolia (noni). J Pharm Pharmacol. 2000;59:1587-1609.

[17] Mediani A, Abas F, Ping TC, et al. Influence of growth stage and season on the antioxidant constituents of Cosmos caudatus. Plant Foods Hum Nutr. 2012;67:344-350.

[18] Singleton VL, Orthofer RM, Lamuela-Raventos RM. Analysis of total phenols and other oxidation substrates and antioxidant by means of Folin-Ciocalteau reagent. Methods Enzymol. 1999;299:152-178.

[19] Brand Williams W, Cuvelier ME, Berger C. Use of free radical method to evaluate antioxidant activity. LWTFood Sci Technol. 1995;28:25-30.

[20] Tsujita T, Takaichi H, Takaku T, et al. Antiobesity action of epsilon-polysine, a potent inhibitor of pancreatic lipase. J Lipid Res. 2006;47:1852-1858.

[21] Peschel W, Sanchez-Rabaneda F, Pleshner A, et al. An industrial approach in the search of natural antioxidants from vegetables and fruit wastes. Food Chem. 2006;97:137-150.

[22] Sultana B, Anwar F, Ashraf M. Effect of extraction solvent/technique on the antioxidant activity of selected medicinal plants. Molecules. 2009;14:2167-2180.

[23] Thoo YY, Ho SK, Liang JY, et al. Effects of binary solvent extraction, time and extraction temperature on phenolic antioxidants and antioxidant capacity from mengkudu (Morinda citrifolia). Food Chem. 2010;120:290-295.

[24] Alothman M, Bhat R, Karim AA. Antioxidant capacity and phenolic content of selected tropical fruits from Malaysia with different solvents. Food Chem. 2009;115:785-788.

[25] Moreno DA, Illic N, Poulev A, et al. Effects of Arachis hypogaea Extract on lipid metabolic enzymes and obesity parameters. Life Sci. 2006;78:2797-2803.

[26] Roh C, Jung U. Screening of crude plant extracts with anti-obesity activity. Int J Mol Sci. 2012;13:1710-1719.

[27] Sang S, Liu G, He K, et al. New unusual iridoids from the leaves of Noni (Morinda cirifolia L.) show inhibitory effect on ultraviolet B- Induced transcriptional activator protein-1 (AP-1) activity. Bioorg Med Chem. 2003;11:2499-2502.

[28] Hsu CL, Yen GC. Phenolic compounds: evidence for inhibitory effects against obesity and their underlying molecular signaling mechanisms. Mol Nutr Food Res. 2008;52:53-61.

[29] Hsu CL, Wu CH, Huang SL, et al. Phenolic compounds rutin and o-coumaric acid ameliorate obesity induced by high fat diet in rats. J Agr Food Chem. 2009;57:425431.

[30] Buettner R, Scholmerich J, Bollheimer LC. High fat diet: modeling the metabolic disorders of human obesity in rodents. Obes. 2007;15:798-808.

[31] Kim SH, Yang SOK, Kin HS, et al. ${ }^{1} \mathrm{H}$ nuclear magnetic resonance spectroscopy based metabolic assessment in rat model of obesity induced by a high fat diet. Anal Bioanal Chem. 2009;395:1117-1124.

[32] Yamamoto M, Shimura S, Itoh Y, et al. Anti-obesity effects of lipase inhibitor CT-II, an extract from edible herbs, Nomame-Herba on rats fed a high fat diet. Int J Obes. 2000;24:758-764.

[33] Sung YY, Yoon T, Yang WK, et al. Antiobesity effect of Geranium thunbergii extract via improvement of lipid metabolism in high fat diet induced obese mice. Mol Med Rep. 2011;4:1107-1113.

[34] Pak-Dek MS, Abdul-Hamid A, Osman A, et al. Inhibitory effect of Morinda citrifolia L on lipoprotein lipase activity. J Food Sci. 2008;78:C595-C598.

[35] Bajerska J, Wozniewicz M, Jeska J, et al. Green tea aqueous extract reduced visceral fat and decreases 
protein availability in rats fed a high fat diet. Nutr Res. 2011;31:157-164.

[36] Unno T, Osada C, Motto Y, et al. Dietary tea catechins increase fecal energy in rats. J Nutr Sci Vitaminol. 2009;55:447-451.

[37] Drent ML, Larsson I, William-Olsson T, et al. Orlistat (RO 18-0647), a lipase inhibitor in the treatment of human obesity: a multiple dose study. Int J Obes. 1995;19:221-226.

[38] Choi I, Park Y, Choi H, et al. Anti adipogenic activity of rutin in 3T3-L1 cells and mice fed a high fat diet. BioFactors. 2006;26:273-281.

[39] Park SY, Bok SH, Jean SM, et al. Effect of rutin and tannic acid supplements on cholesterol metabolism in rats. Nutr Res. 2002;22:283-295.

[40] Buettner R, Parhofer KG, Woenckhaus SM, et al. Defining high fat diet rat models: metabolic and molecular effects of different fat types. J Mol Endocrinol. 2006;36:485-501.

[41] Lebovitz HE, Bannerji MA. Point: visceral adiposity is causally related to insulin resistance. Diabetes Care. 2005;28:2322-2325.

[42] Kishino E, Ito T, Kiuchi Y. A mixture of the Salacia reticulata (kotala himbutu) aqueous extract and cyclodextrin reduces the accumulation of visceral fat mass in mice and rats with high fat diet-induced obesity. J Nutr. 2006;136:433-439.

[43] Schwartz MW, Woods SC, Porte S, et al. Central nervous system control of food intake. Nature. 2000;404:661-671.

[44] Staigner H, Haring HU. Adipocytokines: fat derived humoral mediators of metabolic homeostasis. Exp Clin Endocrinol Diabetes. 2005;113:67-79.

[45] Hayamizu K, Hirakawa H, Oikawa D, et al. Effect of Garcinia cambogia extract on serum leptin and insulin mice. Fitoterapia. 2003;74:267-273.

[46] Emilsson V, Liu YL, Cawthorne MA, et al. Expression of the functional leptin receptor mRNA in pancreatic islets and direct inhibitory action of leptin on insulin secretion. Diabetes. 1997;46:313-316.

[47] Cases JA, Gabriely I, Ma XH, et al. Physiological increase in plasma leptin inhibited insulin secretion in vivo. Diabetes. 2001;50:348-352.
[48] Staiger H, Tschritter O, Machann J, et al. Relationship of serum adiponectin and leptin concentrations with body fat distribution in humans. Obes Res. 2003;11:368-372.

[49] Tschritter O, Fristche A, Thamer C, et al. Plasma adiponectin concentrations predict insulin sensitivity of both glucose and lipid metabolism. Diabetes. 2003;52:239-243.

[50] Bruno RS, Dugan CE, Smyth JA, et al. Green tea extract protect leptin-deficient, spontaneously obese mice from hepatic steatosis and injury. J Nutr. 2008;138:323-331.

[51] Barnea M, Shamay A, Stark AH, et al. A high fat diet has a tissue specific effect on adiponectin and related enzyme expression. Obes. 2006;14:2145-2153.

[52] Alvarez-Castro P, Pena L, Cordido F. Ghrelin in obesity, physiological and pharmacological considerations. Mini Rev Med Chem. 2013;13:541-552.

[53] Raasmaja A, Lecklin A, Li XM, et al. A water-alcohol extract of Citrus grandis whole fruit has beneficial metabolic effects in the obese Zucker rats fed with a high fat/high cholesterol diet. Food Chem. 2013;138:1392-1399.

[54] Stevans CA, Levey AS. Measurement of kidney function. Med Clin North Am. 2005;89:457-473.

[55] Lascano ME, Poggio ED. Kidney function assessment by creatinine based estimation equation. Cleveland Clinic Disease Management Project. Cleaveland: Centre for Continuing Education; 2010.

[56] Pico C, Oliver P, Sanchez J, et al. Gastrcileptin: a putative role in the short term regulation of food intake. Br J Nutr. 2003;90:735-741.

[57] Wang L, Meng X, Zhang F. Raspberry ketone protects rats fed high fat diets against nonalcoholic steatohepatitis. J Med Food. 2012;16:495-503.

[58] Mancebo A, Scull I, Gonzalez Y, et al. Ensayo de toxicidad a dosis repetidas (28 dias0 por via oral del extracto acuoso de Morinda citrifolia en ratas Sprague Dalwey. Rev Toxicol. 2002;19:73-78.

[59] Chearskul S, Kooptiwur S, Chatchawalvanit S, et al. Morinda citrifolia has very weak estrogenic activity in vivo. Thai J Physiolo Sci. 2004;17:22-29. 